\title{
Para uma dimensão ética da prática psicológica em instituições
}

\author{
Ângela Nobre de Andrade \\ Universidade Federal do Espírito Santo. \\ Henriette Tognetti Penha Morato
}

Universidade de São Paulo

\begin{abstract}
Resumo
A Psicologia vem sendo instituída a partir de um pensamento modelar, tendendo a valorizar as configurações identitárias, passíveis de generalizações, em detrimento das diferenças emergentes nas diversas práticas. Estas diferenças são, na maioria das vezes, negadas e/ou avaliadas como desvios, erros e depreciadas quando comparadas ao modelo ou norma. Nos últimos anos, esse modo de pensamento vem sendo questionado e criticado em função da diversidade emergente nas diversas práticas, principalmente naquelas desenvolvidas com populações de baixo nível sócio-econômico, não contempladas nas teorias psicológicas tradicionais $\mathrm{O}$ pensamento modelar, predominante nas sociedades ocidentais, naturaliza valores morais e avalia a vida a partir destes, criando um processo perverso de reprodução de sistemas sociais injustos. Trabalhar numa dimensão Ética significa, exatamente, considerar os valores como criações humanas e acolher a diferença emergente nos diversos contextos como aquilo que resiste à reprodução, como aquilo propiciador de transformações nos modos modelares e excludentes de estar no mundo.
\end{abstract}

Palavras-chave: ética; valores; prática psicológica

\begin{abstract}
Towards an ethical dimension in psychological practice in institutions. Psychology has been instituted from a model thought that tends to value identitarian configurations, susceptible to generalizations, in detriment of the differences which emerge in the diverse practices. These differences are, most of the time, denied and/or evaluated as deviations, errors and depreciated in comparison to the model or norm. In the past few years, this mode of thought has been questioned and criticized in view of the diversity emergent in the diverse practices, mainly in those developed with population of low social-economic level, whom are not contemplated by traditional psychological theories. The model thought, predominant in western societies, naturalizes moral values and evaluates life based on them, creating a perverse process of reproduction of unfair social systems. Working on an Ethical dimension means, exactly, to consider the values as human creations and embrace the difference emerging in diverse contexts as something that resists reproduction, as something which can provide the transformations in the modeler and excluding modes of being in the world.
\end{abstract}

Keywords: ethics; values; psychological practice

$\mathrm{N}$ os últimos anos, no Brasil, temos observado uma demanda crescente dos serviços públicos pelo profissional de Psicologia, o que tem gerado uma maior inserção de psicólogos na rede pública. Essa nova demanda resulta em trabalhos e intervenções junto a uma população com características bastante diversas daquelas com as quais, tradicionalmente, a Psicologia vinha se deparando. Ou seja, a partir da década de oitenta, os psicólogos passaram a atuar junto a uma população de baixo nível sócio-econômico, que apresenta uma realidade psicossocial muito diferente daquela apresentada pelas classes média e alta, alvo dos trabalhos da Psicologia até então.

Durante as décadas de 1960 e 70, as questões políticas não eram priorizadas nos discursos e práticas dos psicólogos. A Psicologia era valorizada em seus aspectos técnicos e científicos, alienada do processo histórico e político no qual estava inserida. Tratava-se de um produto técnico a ser oferecido à população e, para que esta oferta fosse bem sucedida, o psicólogo deveria ignorar os possíveis desafios e críticas à sua atuação e compactuar com os poderes instituídos a fim de garantir a reprodução do sistema social. Este era o perfil da psicologia oficial dominante, transmitida nas academias. Os trabalhos voltados para uma população de baixa renda eram marginais e desenvolvidos por psicólogos que exerciam, também, uma militância política (Andrade, 1996; CRP06, 1994; Freitas, 1996).

A partir da década de 1980, assistimos ao surgimento de uma nova problemática na Psicologia, advinda, principalmente, de sua inserção na rede pública. Até esse período, as instituições públicas não possuíam psicólogos em seus qua- 
dros, com raras exceções, tais como alguns hospitais psiquiátricos, por exemplo. Arrancado de seu papel técnico e cientificista e sustentado por uma suposta unidade da Psicologia, o psicólogo brasileiro vê-se diante de uma série de questões político-sociais que atravessam o fazer psicológico e apontam para o caráter alienante das práticas tradicionais. As questões agora mudam de foco e problematizam a própria função da psicologia. Esta deve seguir trabalhando a partir de teorias e técnicas importadas, em uma pseudo-universalidade, ou deve tentar escutar a real demanda da população brasileira? Como construir práticas que atendam a essa demanda de modo a contextualizar as problemáticas emergentes em cada comunidade, desenvolvendo trabalhos de transformação das relações injustas e excludentes e não reproduzindo o sistema sócio-econômico dominante? (CFP, 1988; 1994).

Tais questionamentos passam a atravessar todas as áreas da psicologia, principalmente a emergente - e ainda marginal - Psicologia Social. Presenciamos nos profissionais desta área uma luta constante em apontar os aspectos políticos das práticas psicológicas e o conseqüente compromisso do psicólogo com os efeitos sociais de seus trabalhos. O crescente envolvimento com as populações excluídas vem gerando desafios e angústia para os psicólogos compromissados com uma transformação social. Para que esta se efetive faz-se necessária uma outra postura, uma outra forma de conceber as relações sociais, o homem, a vida. A cientificidade neutra do psicólogo já não mais se sustenta e os aspectos ético-políticos de suas práticas passam a ser alvo de reflexões e questionamentos.

A pluralidade de teorias e práticas psicológicas, muitas vezes antagônicas, nos remete a questionar o debate epistemológico que tem predominado na história da psicologia, para ressaltarmos a importância da dimensão ética de nossas práticas. Ou seja, na medida em que não há acordo entre as diversas teorias psicológicas sobre o próprio objeto de estudo, métodos ou técnicas, o debate entre elas sobre a verdade de seus modos de produção de conhecimento passa a ser, na maioria das vezes, infrutífero e vazio (Figueiredo, 1994; 1995; George, 1992; Lupo, 1995).

\section{Criando outros paradigmas ou sensibilidades}

Ética aparece, em geral, na história da filosofia, como a ciência da conduta que se apresenta em duas concepções fundamentais: 1) a Ética considerada como ciência do fim para o qual a conduta dos homens se deve dirigir e dos meios para atingir tal fim, deduzindo tanto o fim quanto os meios da natureza do homem; 2) a Ética considerada como ciência do móvel da conduta humana, procurando determinar tal móvel com vistas a dirigir ou disciplinar tal conduta. São duas linguagens diferentes e, enquanto a primeira fala do ideal a que o homem está dirigido pela sua natureza, supondo assim uma essência ou substância do homem, a segunda fala dos motivos ou das causas da conduta humana e pretende se ater ao conhecimento dos fatos (Abbagnamo, 1962).

Ambas as concepções se relacionam, entretanto, intimamente, quanto ao estabelecimento de regras ou leis gerais para a conduta humana; leis baseadas numa suposta nature- za ou essência do homem ou leis baseadas num suposto conhecimento generalizável dos motivos da conduta humana. Essas concepções de Ética, que vêm desde a antiguidade e, com algumas alterações, continuam permeando a modernidade, são confundidas com a Moral e, muitas vezes, tomadas como sinônimos. Supõem valores morais que possam disciplinar e avaliar a conduta humana.

$\mathrm{Na}$ presente reflexão, o conceito de Ética será utilizado com uma significação bastante diferente. As concepções descritas acima serão consideradas aqui como exemplos de uma Moral. Ao longo desta análise, Ética se referirá mais propriamente à etimologia de éthos (que, originariamente, significava assento, morada), designando posturas existenciais e/ou concepções de mundo capazes de dar acolhimento, assento ou morada à alteridade. Acolhimento à diferença produzida na processualidade que não se deixa capturar ou reduzir a ideais ou leis de conduta. Não se trata aqui de negar os valores como vetores de uma sociedade, mas de instituir valores supramorais tanto no nível das sensibilidades, quanto no do pensamento; uma nova maneira de sentir e pensar que não se baseia em supostas verdades fixas e gerais, mas acolhe a vida em sua contínua processualidade e transformação. Trata-se de uma serenidade frente à multiplicidade, ao acaso, àquilo que nos transforma sem nos darmos conta; o avesso dos valores morais, que supõem uma ordem natural e imutável do mundo. ${ }^{1}$

$\mathrm{O}$ pensamento tradicional e dominante nas Ciências Humanas e Sociais trabalha a partir de modelos identificáveis e generalizáveis. Trata-se de um pensamento herdado desde Platão, predominante nas sociedades ocidentais, que avalia a vida a partir de uma crença metafísica. Esta pode ser definida, basicamente, como uma crença inabalável de que o pensamento racional, seguindo as trilhas da causalidade, é capaz não somente de conhecer o ser humano em sua totalidade, mas também de corrigi-lo.

Trata-se de um modo de conceber o mundo ou a natureza com duas faces: a essência e a aparência. A crença metafísica supõe que o conhecimento é capaz de penetrar conscientemente na essência, no fundo das coisas, separando a verdade da aparência; esta separação está na base da criação das categorias de erro e de mal que aparecem como opostas à verdade ou à essência das coisas. Esse pensamento é constitutivo tanto das ciências quanto das religiões ocidentais, pois estas se instituem a partir da crença em verdades que possibilitem a criação de modelos e leis universais. A vida aqui é concebida como algo a ser explicado a partir do conhecimento das causas e estabelecimento de universais que a regulamentam; tudo aquilo que escapa ou extrapola a essas leis é considerado um erro, um desvio que deve ser corrigido. A processualidade é capturada em intersecções estáveis e definíveis, e a diferença advinda dessa processualidade é considerada uma "des-ordem" do sistema (Machado, 1990; 1994; Marton, 1993).

O pensamento cristão vem reforçar esta idéia de verdade, assentada, então, em um fundamento divino. Com a "morte" de Deus, a crença em uma verdade universal continua presente no projeto moderno de constituição de subjetivida- 
de, não mais sob o império de Deus, mas sob o império da Razão. Por meio desta, o homem é capaz de encontrar as leis que regem a natureza e, desta forma, estabelecer um controle sobre si mesmo e sobre o mundo. Esse si-mesmo, essa identidade autocentrada, bem distinta e individualizada, vem a ser o suporte da psicologia, quando esta se institui enquanto ciência autônoma.

Pensar o mundo desta forma resulta não só valorações morais (códigos e regras de vida), presentes em nosso modo de representar o bem social, mas também no nosso modo de ser afetado pelo outro, de acolher a vida. Ou seja, para esse pensamento universalizante, o fundamento da vida está na identidade de cada coisa consigo mesma, na idéia de uma estabilidade espaço-temporal, e tudo aquilo que escapa a essa ordenação é considerado desviante e deve ser excluído. Negase qualquer possibilidade de um mundo em permanente instituição e engendramento. Trata-se do lugar seguro daquele que pretende, sob o domínio da racionalidade, dar conta da produção da diferença através de sua negação e/ou exclusão.

Entretanto, no momento do encontro com o outro, em nossas práticas, esse domínio do saber não funciona como lugar seguro; não traz respostas exatas ou verdadeiras; não alivia a angústia perante a alteridade que aparece no encontro. Assim, nega-se a alteridade reduzindo o outro a interseções bem delimitadas no tempo e no espaço ou, o que é mais raro, acolhe-se a alteridade como irredutível, como fundamento do encontro. No primeiro caso, temos o homem teórico, portador de um saber racional que explica as irracionalidades (os desvios) e acredita deter os meios de controlá-las ou ajustá-las à norma. No segundo, temos o homem ético, que se deixa afetar pelo estranho, por aquilo que não é da ordem do representacional ou de seus códigos familiares, e ao acolher a alteridade e a produção de diferença emergente, vive um processo transformador e instituinte de novos modos de estar no mundo. Transmutase do lugar da explicação sobre para o lugar do aprender com ou aprender entre.

\section{Do especialista a uma produção coletiva}

Esse outro modo de conceber a vida, de conceber a própria Psicologia, traz desafios importantes para nossas práticas cotidianas, uma vez que se contrapõe, radicalmente, ao modelo dominante. Trata-se, antes de tudo, de um deslocamento do saber, de uma outra postura ética em que não existe um saber dado à priori, ou uma verdade a ser transmitida, mas uma construção conjunta de sentidos. Nas práticas institucionais faz-se necessário, pois, que o psicólogo se despoje do lugar de especialista, portador de um saber a ser transmitido e passe a funcionar como um mediador, um entre, que acolhe a produção emergente nos diversos encontros.

Observamos, hoje, uma gama enorme de profissionais trabalhando em instituições. Entretanto, e isto é bastante preocupante, os psicólogos tendem a reproduzir os modelos tradicionais de intervenção travestidos em técnicas ou métodos alternativos. Por exemplo, é comum se falar em trabalhos com grupos, ou trabalho coletivo, como se o número de participantes na intervenção garantisse, por si só, um trabalho efetivamente comunitário e transformador. O psicólogo permanece, entretanto, no lugar de quem porta um saber sobre o outro, permanecendo como um especialista centrado nos "problemas psicológicos" daquela população. Reproduz, juntamente com o grupo, os valores e crenças dominantes, de que os problemas ali vividos são originados, fundamentalmente, por fatores psíquicos.

La práctica de este profesional revela la creencia en que los problemas vividos por la población son originados, fundamentalmente, por factores psíquicos. Las condiciones concretas de vida de la población no son consideradas como centrales en el trabajo a ser realizado, una vez que este tipo de actuación focaliza como importante el tratamiento de los problemas de orden psicológico, comprendiéndolos como derivados de la estructura interna o subyacente a la personalidad. (Freitas, 1994, p. 146)

Encontramos também o oposto, ou seja, aqueles profissionais que percebem a população apenas em suas deficiências sócio-econômico-culturais e desenvolvem um trabalho assistencialista, com o intuito de "conscientizar" e "ajudar" tal população em suas reivindicações e lutas político-sociais. Este psicólogo também aparece como um estranho àquele grupo, na medida em que ele desconhece suas potencialidades, suas problemáticas reais e os modos de enfretamento que a população desenvolve. Esta permanece em um lugar passivo enquanto o profissional age em favor dela. Trata-se da posição do

concientizador de la comunidad, que plantea una intervención comunitaria llevada a cabo por el "concientizador iluminador", que se ve a si mismo salvador de personas "apáticas" o "alienadas” y que busca canalizar la participación a través de instancias controladas por centros de poder. (Montero, 1994, p. 34).

Em ambos os exemplos acima, os profissionais permanecem na crença e postura de quem sustenta um saber sobre o que é melhor, mais saudável, ou mais transformador para aquele grupo. Permanece na dimensão moral que pressupõe verdades universais sobre os relacionamentos psicossociais. A dimensão ética de acolhimento à produção da diferença, que advém, exatamente da produção de conhecimento emergente no encontro, no grupo, está completamente ausente nesta postura ditadora de a prioris.

Esta passividade, necessária a um sistema político-social excludente como o nosso, é sustentada por determinadas crenças e valores de verdade, disseminados na sociedade. Assim, ao se avaliar os diversos comportamentos e relações como "desviantes", culpabilizando-se os indivíduos, naturaliza-se as problemáticas apresentadas e, no mesmo movimento, esvaziam-se possibilidades de ações concretas no exercício da cidadania. Um bom exemplo dos desafios para as práticas institucionais do psicólogo pode ser encontrado nos trabalhos junto ao Conselho Tutelar (CT), órgão instituído pelo Estatuto da Criança e do Adolescente (ECA), obrigatório em todo município. O Conselho Tutelar aparece, exatamente, como um espaço importante para que ocorra o exercício da cidadania, na medida em que foi criado como um órgão 
executivo, autônomo, tendo por objetivo assegurar o cumprimento dos direitos das crianças e adolescentes. Trata-se de uma proposta de participação civil que requer, para tal, um repensar sobre a sociedade e sua atuação cotidiana quanto a questões ligadas à democracia, solidariedade, responsabilidade, cidadania, entre outras, uma vez que este processo implica uma participação comunitária como um dispositivo coletivo de ação.

A Psicologia vem sendo convocada a participar dos conselhos tutelares. Esta atuação, entretanto, pode se dar de duas formas básicas e absolutamente antagônicas. O psicólogo pode permanecer no lugar de especialista de "problemas emocionais", tratando a população envolvida (conselheiros e moradores) como indivíduos com dificuldades pessoais a serem resolvidas ou, ao contrário, pode se dedicar a desmistificar tais crenças, provocando o grupo para ações concretas e conjuntas. Tal postura exige, entretanto, que o psicólogo se despoje de um saber teórico modelar, para se implicar política e eticamente com as problemáticas ali suscitadas. Estas são sempre contextuais e multifacetadas, não comportando uma explicação simplificada ou um saber psicológico apriorístico. Trata-se, antes, de um lugar de riscos, em que a experimentação, as tentativas de que algo se produza estão sempre presentes, num esforço permanente de trabalho conjunto e solidário; trabalho em que não existe um especialista a dar respostas, mas uma construção conjunta de novos sentidos e ações.

Não se trata, aqui, de descaracterizar o psicólogo de seu saber de ofício. Pelo contrário, trata-se de um resgate desta dimensão ética que deveria ser imanente ao saber de ofício do psicólogo. Este, em sua prática cotidiana, exerceria a função de estar promovendo e acolhendo a produção comunitária, em um processo permanente de desmistificação de verdades naturalizantes e universalizantes geradoras de injustiças e exclusão sociais. Um trabalho voltado para trans-formações das relações sociais exige um desmonte permanente das cristalizações que impedem a instituição de outros modos de estar no mundo; de outras "formas" de afetamento, em que a diferença não aparece como algo a ser negado ou excluído, mas exatamente como aquilo que possibilitará a criação, as mudanças nos sistemas - pensamento, relações, crenças, entre outros - cristalizados.

\section{Dimensão ética e atenção psicológica como prática clínica em instituições ${ }^{2}$}

Como discutido anteriormente, dentre as inúmeras vicissitudes do cenário da contemporaneidade, sua estruturação social estimula formas malogradas de subjetivação. Em um percurso histórico de transformações sucessivas do ethos ${ }^{3}$, que acompanharam as transformações sociais e econômicas, os modos de ser e fazer da atualidade não encontram referenciais. Se a ética do liberalismo jamais garantiu uma vida relativamente protegida, embora a apregoasse, as práticas disciplinares são cada vez mais utilizadas pela sociedade administrada para impor modos de ordenação da vida pública, que passam a transcender este campo para alcançar as existências individuais.
No confronto entre a posição liberal e a disciplinar, entremeados pela axiologia romântica como resposta, em busca da restauração e pertencimento da dignidade do indivíduo, estão situados os modos de habitar o mundo na atualidade, nos quais o indivíduo não habita realmente nenhuma casa, já que está disperso em três possibilidades de morada (Figueiredo, 1995). Nesta perspectiva, com o espaço para a manifestação da subjetividade reduzido, a constituição dos sujeitos tornase cada vez mais dificultada. Em contrapartida, esse modo de organização da vida contemporânea favorece a constituição de indivíduos ${ }^{4}$, reduzindo as possibilidades de transformação do todo social, ao mesmo tempo em que produz modos de vida cada vez mais estáticos e estagnados.

O indivíduo contemporâneo é, portanto, aquele capaz de adaptar-se, calando aquilo que, em sua interioridade, questiona ou é tocado no contexto de seu existir-em-situação, passando a considerar problemas ou situações em sua frieza, buscando a excelência e a eficácia. Essa redução cada vez maior de espaços para a subjetividade e modos de subjetivação atrofiados, implica também reduzir as possibilidades de reflexão acerca do agir social, gerando uma vinculação perversa aos grupos sociais, na medida em que promovem a assimilação direta, pelo indivíduo, dos modos de ser dos grupos sociais a que pertence. Sem uma mediação reflexiva, esta assimilação permite ao indivíduo uma idealização do grupo. Por um lado, já é, em si, uma violência contra o sujeito, na medida em que viola os espaços para a reflexão subjetiva, e, de outro, estimula a violência contra aqueles que não pertencem ao grupo, já que, em tal processo de massificação, toda alteridade é ameaçadora e deve ser eliminada.

Nesse contexto emerge violência, compreendida como possuindo sentido de existir e se traduzindo em uma relação de forças, que envolve pessoas, interações e os modos de funcionamento. Os atuais discursos de diferentes grupos, referentes à possibilidade e promessa de erradicação completa da violência, remetem-se a uma conduta totalitária e massificada do funcionamento da sociedade. Essa conduta tende a interpretar o sentido da violência fora de sua real complexidade de relações na organização social, dando a ela a única possibilidade de vincular-se como sentido ao mal, ao ato de causar dano e prejuízo. Com essa categorização, o pânico e o medo são inseridos diariamente em nossas casas pelos meios de comunicação de massa como forma de submetermo-nos passivamente à lei e renunciarmos a toda violência que habita em nós próprios e a todos os outros sentidos que a violência pode comunicar em nossa atual organização social.

Nas organizações, seus objetivos, valores e seu processo de socialização são propostos constantemente aos indivíduos, ao mesmo tempo reduzindo ainda mais o espaço de sua subjetividade e tendo por finalidade atá-los firmemente às malhas por elas tecidas. A "cultura da organização" muitas vezes ganha cunho da dimensão do sagrado, substituindo a religião na tarefa de garantir tanto um sistema de significações quanto a tranqüilização, ao transformar em ponderável a imponderabilidade do destino, ao negar a existência do chaos $^{5}$. Isto leva o indivíduo a sacrificar-se pelas metas por elas perseguidas, adentrando irrefletidamente em um sistema totalitário. 
Neste quadro social atual de desamparo e sofrimento humanos, com reduzido espaço para a subjetividade, no qual uma das expressões mais marcantes ocorre no espaço público de instituições e organizações (Levy, 2001), é coerente que um laboratório universitário ${ }^{6}$ tenha sido procurado para uma intervenção psicológica por instituições relacionadas à Segurança Pública e à Justiça, já que é em seu contexto que esta realidade mostra sua face mais diretamente perversa. Duas experiências, em unidades de internação da FEBEM e batalhões da Polícia Militar, relatadas mais adiante, potencializam este quadro, propiciando um olhar atento e cuidadoso aos modos de subjetivação engendrados pela violência perpetrada pelas organizações sociais na contemporaneidade.

Partindo da insuficiência da prática psicológica na experiência clínica, busca-se compreender o mal-estar contemporâneo, apontado, insistentemente, como sofrimento humano num mundo conturbado. O tema se impõe como urgência ${ }^{7}$ visto que essa prática questiona a transição de paradigmas científicos, atitudes fundamentalistas e niilistas, ao lado da globalização da economia, avanços tecnológicos propiciadores de intensa aproximação de misturas e pulverização de diferenças. Como conseqüência dessa transição, as referências que respaldavam a compreensão do sujeito moderno, ancoradas pela consciência e pela racionalidade, estão sendo questionadas. Do mesmo modo, também se põem em questão as figuras subjetivas, concebidas como relativamente estáveis para respaldar a construção de um modo de ser, apresentando a noção de ordem ligada ao equilíbrio, pela separação nítida entre interior e exterior, através das quais o sujeito é fundamento de sua própria existência: funda sua liberdade e constrói sua essência. Tal compreensão, início da experiência clínica, demanda uma ressignificação.

Deparamo-nos, hoje, com contornos subjetivos efêmeros, nos quais a fragmentação da subjetividade ocupa posição fundamental. Essa fragmentação, apresentada como fragmentação do espaço e, ao mesmo tempo, como contração do espaço-tempo, não é apenas uma nova forma de subjetivação ${ }^{8}$, mas a matéria-prima por meio da qual outras formas de subjetivação são constituídas. Assim, é necessário descrever o mal-estar contemporâneo pela questão da subjetividade, pois mal-estar, dizendo do sujeito, implica o campo da subjetividade.

Nesse sentido, cartografar ${ }^{9}$ o mal-estar contemporâneo é atentar para o modelo de ciência e suas conjunções, nosologias comunicacionais e cognitivas, efeitos nas estruturas clássicas e modernas de verdade, sujeito, história e mundo. Sofrimento como mal-estar representa um fenômeno perturbador atual, implicando considerar a "reviravolta" subjetiva da realidade, direcionando o foco para os processos de constituição da subjetividade e impasses experienciados na contemporaneidade. Implica "reviravoltear" a subjetividade, fora do âmbito da identidade e da representação, demandando os múltiplos processos de subjetivação, engendrados nas dimensões sociais, culturais e temporais. Refere-se a questões como: os instrumentos compreensivos da Psicologia apreendem as novas modalidades de inscrição das subjetividades contemporâneas? Legitima-se repensar sistemas psi- cológicos, por representarem subjetividade e seus impasses na modernidade? Como aproximar o que há de "sofrente" nas novas formas de subjetivação? Como circunscrever o campo do mal-estar contemporâneo em que essas modalidades se constituem?

A atividade clínica e a pedagógica não fogem a um predomínio da técnica, fenômeno essencial da Idade Moderna. A clínica, afastando-se de sua peculiaridade originária referente ao debruçar-se sobre o leito do "doente", passa, cada vez mais, a privilegiar procedimentos técnicos. Desse modo, hoje, o clínico é entendido e valorizado como especialista. Nessa composição, o momento clínico inicial, com toda sua potencialidade de promover uma confiança terapêutica através da atenção e acolhimento, é reduzido a uma atividade de triagem, a qual encaminhará os pacientes aos respectivos especialistas, que, através da mediação da técnica, deles tratarão.

Por sua vez, no âmbito pedagógico, os currículos dos cursos de ciências humanas e biológicas têm cada vez mais contemplado quesitos técnicos, visando a formação de especialistas, em detrimento de uma formação humanista, relevando a filosofia, a literatura e as artes em geral. Nessa ótica, é esperado e apreciado que, por exemplo, o psicólogo atue primordialmente enquanto um especialista em sua atividade profissional; em seu consultório ou em instituições, ele deverá manter-se numa neutralidade, afastando-o da condição fundamental da cidadania: do ouvir e do ser ouvido em praça pública.

No entanto, esse modelo técnico-científico mostra sinais de esgotamento. No âmbito da saúde mental, tanto a psiquiatria quanto a psicologia não têm, institucionalmente, ainda, apesar dos esforços do movimento antimanicomial, conseguido responder às demandas sociais e culturais emergentes. As instituições psiquiátricas manicomiais revelaram-se depósitos de pessoas, subtraindo-lhes a própria humanidade ao condená-las a um diagnóstico estigmatizante, gerador de exclusão social e cultural, alijando-as de sua cidadania. Os manicômios falharam em sua tarefa de cuidar do "doente mental", não conseguindo reverter e nem sequer minorar seu sofrimento; ao contrário, esse sofrimento aumentou, pois passou a relacionar-se ao não sentido de ser desses pacientes. Do mesmo modo, no âmbito da educação, procedimentos pedagógicos alinham-se por modelos disciplinares de conduta, desconsiderando o direito de aprender.

Dessa forma, instituições de saúde e educação constituem-se, na maioria, em lugares não implicados com uma atenção para resgate de sentido. Nelas, os sujeitos sociais são despejados, destituídos de razão e/ou bem-estar ou de possibilidades de aprendizagem; assim, constituem-se lugares onde sagra um sofrimento confinado e reverberado, revelando um sujeito, e as instituições que deles cuidam, como dependentes de um tecido social e cultural, cujos sistemas de representação e simbolização determinam modos de ser adequados e ajustados. Enquadrados na des-razão e no des-conhecimento, os sujeitos sociais são condenados tanto ao exílio social (pela des-consideração institucional), como também ao exílio de si mesmos (pelo des-alojamento existencial). 
É patente que o contexto social, político, econômico e cultural contemporâneo clama por mudanças nas abordagens implicadas tanto na concepção e implementação de saúde e educação quanto na pedagogia da formação profissional de seus agentes. Propor alternativas de trabalho técnico e reflexões teóricas para profissionais que lidam com uma população resultante de uma nova ordem mundial, apresenta-se como uma tarefa desafiadora para psicólogos.

Em face desse enfoque de realidade, imposta progressivamente com contundência e pungimento, cabe a pergunta: seria possível abrir outras possibilidades de práticas clínicopedagógicas, em saúde e educação, para o mal-estar no contexto contemporâneo? Talvez, um caminho possível seria buscar a etimologia dos termos saúde, educação, sofrimento, política e ética, a fim de articular sentido entre cada um, como um encaminhamento para uma reflexão sobre tal questionamento da prática psicológica em instituições.

\section{Etimologia como criação de sentido}

É da perspectiva da significação da linguagem como criação de sentido que se impõe uma retrospectiva etimológica, reencontrando a atribuição de significado a termos recorrentes na compreensão do sentido da condição humana. Afinal, no percurso histórico de uma língua, tais termos passaram a aderir-se a significados precisos e determinados, destituindo-os de seu uso originário como utensílio para a comunicação de sentido entre homens.

Segundo o Webster (1974), saúde vem do latim salus, significando condição (orgânica ou organizacional) benéfica, de bem-estar, de segurança. Refere-se à cura (healein, em inglês antigo), como promoção de integridade e/ou cuidado. Talvez desse termo tenha derivado saudação, como forma de demonstrar respeito e reconhecimento àquele do qual nos aproximamos. Aproxima-se de clínica e de cuidado, tarefas cotidianas e pertinentes ao universo do fazer psicológico no âmbito da saúde. Por outro lado, educação, do latim educere, de e+ducere, ou seja, e=para fora, e ducere $=$ conduzir, é trazer, fazer movimento em direção a alguém. Implica debruçarse ou inclinar-se a uma forma de cuidar para que o outro se conduza adiante. Desse modo, ambos parecem articular-se à prática psicológica clínica. Dizem respeito a dirigir-se a alguém de modo a fazê-lo conduzir-se adiante em sua experiência, destinando-se ao seu bem-estar. Assim, saúde e educação aproximam-se tanto pelo sentido de promoção de cuidado e integridade, quanto de demonstração de respeito e reconhecimento, via saudação.

Comprometida com atenção e cuidado para que o sujeito se conduza na direção de seu bem-estar, ou de resgate de sentido, a prática psicológica inclina-se para acolher o sofrimento humano como perda de sentido. Etimologicamente originário do grego pathos, sofrer assume o significado de sentir, experienciar, tolerar sem oferecer resistência, ser afetado, dizendo da condição de se pôr em movimento por qualquer emoção. Em latim, sofrer origina-se de subferre, referindo-se a suportar por debaixo, implicando dois significados: tolerar um peso e sustentar um peso. No primeiro, sofrer diz respeito a uma dor, ao passo que no segundo diz de uma força ou de um poder ser. Assim, em ambas as origens, sofrimento referese à situação de ser afetado pela ambigüidade própria da condição humana. Diz da dor frente ao desamparo do homem na sua tarefa de existir, suportando a inospitalidade dos acontecimentos para conduzir-se adiante.

As profundas mudanças sócio-culturais em curso atualmente, requisitando alternativas para a promoção de saúde e educação, necessitam ser contempladas pela oferta de reflexões teórico-práticas para a formação, de profissionais dessas áreas, mais pertinente às demandas de seus serviços no contexto social contemporâneo, e não por significados institucionalizantes atribuídos historicamente. Assim, pela etimologia de saúde e educação, legitima-se a criação de uma cultura de participação da comunidade para promover sua própria saúde e apropriar-se de sua educação, assim como criar uma ambiência para especificidades e diferenças de perspectivas entre os atores sociais envolvidos.

No entanto, o homem só é capaz de chegar ao outro pela palavra ou pela cultura, através dos usos, costumes, preceitos e normas, como um corpo moral normativo. Desse modo, o comprometimento social, implicado também na prática de orientação fenomenológica existencial, é uma dimensão a ser considerada por aqueles engajados em promover o bem estar pessoal e profissional de pessoas. Uma prática sob tal ótica pode ampliar o espectro de ação humana, permitindo uma atuação responsável para com a pluralidade da condição pósmoderna da vida do homem e seu sofrimento.

Assim, desembocamos numa perspectiva ética no trato do político. A palavra ética, do grego ethos, significa modo de ser, ou maneira pela qual a pessoa e a sociedade se mostram; essa manifestação dá-se de formas variadas, fundando a habitação quer do lar, quer da polis (em grego, cidade, país, lugar). Aí se encontra uma articulação entre ética e política, comportando a mesma ambigüidade de sanção (dever) e expressão (direito) com prudência e serenidade. É possível, por esta perspectiva, impor-se uma reflexão acerca da dimensão ética em práticas psicológicas em instituições.

Retomando Figueiredo (1995), quanto aos significados de ética, há uma dimensão ética da existência humana referente ao campo de relação de um indivíduo com outros, no contexto da antropologia filosófica. Nessa ação interativa, o que importa "não é só e principalmente a sobrevivência do agente, mas também sua imagem e sua estima perante os outros e perante si mesmo. Efetivamente, há sempre uma reflexividade, uma relação de um para consigo mesmo, implicada numa conduta ética" (p. 28). Dessa forma, ética e política referem-se, simultaneamente, a privado e público, intimidade e exposição, cuidado e segurança, identidade e cidadania, saúde e normas, direitos e deveres, interior e exterior.

Assim, a construção de regras e critérios confiáveis de decisão, na escolha de modos de ser e fazer, gerar e gerir a própria vida, passou a calcar-se em experiências subjetivas individualizadas, acentuando uma crescente separação entre indivíduos e coletividades às quais pertencem. Por outro lado, é exatamente a incerteza em relação à legitimidade das "verdades" assim constituídas que gera uma vinculação perversa em relação ao grupo, já que, incerto sobre a legitimidade do 
seu saber e fazer, o indivíduo passa a apoiar-se cegamente nos valores, atitudes e crenças do grupo do qual participa.

Dessa forma, o modo de constituição desses grupos e sua vinculação ao quadro maior da sociedade geram um modo de ação no qual a alteridade (outros grupos, outras idéias, outras propostas políticas, religiosas ou científicas) passa a ser considerada uma ameaça, devendo ser eliminada: um grupo não pode suportar outra verdade além da sua. Assim, florescem as condutas totalitárias e massificadas, fruto da intolerância e do fanatismo (Enriquez, 2001), revelando que a ética como ideologia é perversa já que, tomando o presente como fatalidade, anula a marca essencial do sujeito ético e da ação ética. Aborta-se o sujeito social: aquele agente para a atuação de sua liberdade de escolha como atividade reflexiva e crítica acerca de ações, possivelmente, no passado, eleitas para o presente, sendo este uma passagem apenas transitória, pela possibilidade do futuro como abertura do tempo humano.

Contudo, as normas societárias têm a função de ordenar o caos no qual a liberdade, ilimitada e não estruturada, pode levar os indivíduos a uma permanente guerra de um para com todos os outros, viabilizando o agir somente segundo interesses privados. Uma tal situação gera insegurança, tensão e conflito, podendo destruir a todos. Novamente, a violência se apresenta como modo humano no jogo ambíguo entre o público e o privado, uma vez que, para obter proteção, a liberdade das individualidades deve sofrer restrições.

Assim, pode-se pensar que a sociedade estrutura seus padrões de acordo com uma lógica de criação de poder soberano para proteger igualmente todos os seus membros, como garantia de melhor qualidade de vida. No entanto, Pellegrino (1983) diz que, "na contemporaneidade, se verifica que o pacto social instalado para a proteção social traiu seus próprios propósitos e foi quebrado" (p. 2). Desviando-se completamente do compromisso de garantir a convivência humana dentro de padrões aceitáveis de segurança, tal pacto veio a reboque de uma economia política despótica, em que as necessidades e interesses humanos ficam atrelados às idiossincrasias do mercado e do capital, fetichizados como um bem supremo a ser prioritariamente atendido. Esta é uma forma de compreensão da injustiça social que graça no mundo globalizado. Numa ampla visão histórica, pode-se encarar essa situação como emergência [10] de

encontros conflitantes e tencionais entre opressores e oprimidos, ou um modo clássico de relação que conduz à ética categorial do bom e do mau, incluído e excluído, igual e diferente, independente e dependente, enquadrados e marginalizados, aqueles e os sem teto. Aparece a condição marginal: sem nome (identidade), nem endereço (cidadania), absolutamente sem referência alguma. Isso revela uma estrutura social perversa, na qual o comportamento desviante não é uma questão de inadaptação cultural, mas antes um problema político vinculado a uma problemática de identidade. (Morato, 1994, p. 14)

Tal contexto conduz a repensar tanto a ação quanto a formação de profissionais, atuantes no setor da saúde e do desenvolvimento humano, e a problematizar a questão do sofrimento humano em diferentes situações: em consultório privado, em instituições de saúde, em programas educacionais para populações marginalizadas. É essa dimensão da ética que demanda repensar a própria clínica, redirecionandolhe o sentido de modo a contemplar o espectro da experiência do ser humano, plural e singular ao mesmo tempo, atendendo a todas as formas de manifestações e expressões pessoais, além da tradição cultural. Diz respeito à crença no ato transformador que, para além da culpa assistencialista, dispõe-se a cuidar de quem sofre, aceitando o desafio de confronto com o estranhamente diferente, esperando que o assombro com o estranho, com acontecimentos inesperados propiciados por essa abertura para o mundo, possibilite a criação de outras dimensões à compreensibilidade da humanidade do homem.

Mas, como seria possível abrir possibilidades de práticas clínico-pedagógicas em saúde e educação no contexto contemporâneo? Uma possibilidade seria oferecer subsídios teóricos para uma formação de profissionais de saúde e educação mais pertinente às demandas de seus serviços no contexto social contemporâneo, baseando-se em projetos de extensão universitária como pesquisa interventiva. Compreendida a dimensão ética para o humano, pode ser possível discutir uma prática psicológica direcionada por essa tensão originária, própria no sujeito. Possibilitaria encontrar sentido para uma prática que contemplasse esse sujeito/agente e seu conflito diante de pressões inevitáveis e próprias de sua humanidade. Enfim, busca-se reconfigurar uma prática psicológica que privilegie o sofrimento do sujeito social situado conflitadamente em suas formas de organização.

\section{Re-configurando uma prática psicológica}

No âmbito da atuação psicológica, o olhar voltado ao sofrimento humano contextualizado preocupa-se em buscar abordagens teórico-práticas que contemplem as demandas inseridas nesta problemática. Procurando por metodologias interventivas para a inserção de práticas psicológicas em contextos institucionais, alunos de graduação e pós-graduação buscaram, pela cartografia como inserção de atenção psicológica, responder à cultura de cada instituição. Consideravam imprescindível a investigação para um saber mais condizente com a experiência do homem no mundo com outros, aproximando-se do que seria o tácito, o cultural, o étnico e, talvez, o ético. Partindo do contexto social de cada instituição, possibilidades e desafios se impuseram a esses investigadores, inquietos com o sofrimento e desamparo social, refletindo-se narecriação de prática psicológica, ampliadora do fazer clínico do psicólogo para além do sentido instituído.

No contexto pós-guerra, o Aconselhamento Psicológico surgiu como uma modalidade da psicologia clínica, visando a prontidão ao cuidado do sofrimento imediato do outro (Morato, 1999), dando a ver a necessidade de a Psicologia atentar, sofrer e transformar-se, acompanhando as mudanças sociais, como criação de métodos para buscar o bem-estar daqueles que a demandavam para além da cientificidade de investigações, intervenções e teorias. Afinal, constituímos a história e, ao mesmo tempo, somos por ela também constituídos; não podemos separá-la de nós mesmos como objeto de 
estudo, pois "o cliente é um sujeito social, histórico e cultural, é a complexidade e a multireferência que está em jogo e que pode oferecer uma visão de homem não mais fragmentada, mas global e solidária" (Vieira Filho, 1997, p. 3). Referia-se a um modo de ação para se aproximar do fenômeno humano, direcionando a clínica tradicional para a coletividade, considerando o homem um ser situado, contextualizado em uma cultura, num determinado espaço e tempo. No fundamento dessa prática, encontrou-se a articulação entre referenciais teórico e metodológico como valor ético do compromisso científico e social do psicólogo: um posicionamento epistemológico outro acerca de explicações científicas e sua pertinência como destinação para o bem-estar da humanidade (Morin, 1990), redirecionando pesquisas para além dos muros da Universidade (dos laboratórios a ações interventivas em campo), pois essa guinada poderia promover uma prática mais humanizante de atenção psicológica a instituições, reconhecendo seus profissionais como agentes sociais de mudança.

O fundamento desta clínica opta, de um lado, pela perspectiva fenomenológica existencial, dada a condição constituinte relacional da existência humana, revelada no encontro com o outro. Situações de encontro intersubjetivo propiciam, no cotidiano da vida, mudanças para aprendizagem do ser humano e formas de convivência no mundo com os outros, vendo e sendo visto, ouvindo e sendo ouvido (Figueiredo, 1995). Por outro, encontra uma vertente na Psicologia Social Clínica ou Psicossociologia Clínica (Enriquez, 1997; Lévy, 2001), pela qual a intervenção psicológica une olhares de um clínico e de um investigador na situação real dos sujeitos sociais: no cotidiano, constituídos e constituintes de organizações, comunidades e instituições. Entrelaçando as esferas, reconfigurar-se significativamente a transferência de metodologia na formação de agentes sociais de saúde e educação. Conhecer eficácias, dificuldades, limites e responsabilidades desta prática (quanto à demanda da população, usuária dos serviços de instituições públicas), bem como legitimar estágios e projetos de extensão (na parceria entre ciências aplicadas da Universidade e necessidades da comunidade de seu entorno) permitiu reflexões que, pelos desafios da prática em ação, engendram pensar a responsabilidade e o compromisso ético do psicólogo frente às demandas sócioculturais do país.

$\mathrm{Na}$ perspectiva de atendimento à demanda, impôs-se, por um lado, a necessidade de abandono de certas tradições de clínica e teoria psicológica e, por outro, uma alternativa para contemplar as emergências trazidas à Universidade. Recorrendo à perspectiva de psicossociologia clínica com referencial fenomenológico existencial refletimos sobre transformações que o próprio serviço de atenção psicológica, de um lado, e as instituições solicitantes, de outro, sofreram ao longo do tempo. Possibilitou compreender a experiência dessa ação como diferentes formas de "jogo de encaixe", ilustrados por dois relatos breves.

A situação de atendimento em sala ou não, em atendimento numa unidade de internação de adolescentes em conflito com a lei, mostrou como a redução do espaço da subjetividade é estimulada na instituição, sendo necessário inven- tar um outro espaço, como a subdivisão do espaço de Plantão, para poder garantir o espaço subjetivo. Por outro lado, a garantia do espaço de escuta como lugar para a subjetividade na instituição pôde, pela transformação de seus participantes, levar a transformações institucionais. Refletindo sobre a validade das propostas do grupo de plantonistas, os próprios internos começaram a questionar o quanto eles próprios anulam sua subjetividade para poderem pertencer ao instituído, seja esse a instituição do grupo de adolescentes, quanto o da instituição mesma.

Um atendimento numa instituição policial permitiu vislumbrar, também, este duplo aspecto. Escutando a queixa de uma soldado que, encaminhada por seu superior, relatava como, apesar das diversas vicissitudes sofridas na vida, o que não conseguia era suportar exatamente sua relação com este comandante, o Serviço precisou adaptar-se ao funcionamento institucional: recebera um "encaminhamento" do comandante, com caráter, de certa forma, punitivo; mas, por outro lado, permitiu des-construir e reconfigurar esta situação, esclarecendo à soldado que seria atendida apenas se quisesse, para pensar na relação com o comandante e com a instituição, procurando sentido para seu modo de ser no cotidiano profissional e formas de lidar com tais situações.

Ao longo do trabalho, outras formas de explicitar angústias, pertinentes ao pertencer e agir em diferentes instituições se revelaram, tornando os Serviços de Atenção Psicológica lugares não apenas de busca de ajuda direta, mas de legitimação de falas acerca do sofrimento, decorrente tanto do trabalho institucional como de questões subjetivas. Poderia ser este modo de agir desvelador da dimensão políticoética na prática psicológica em instituições?

\section{Referências}

Abbagnano, N. (1962). Dicionário da filosofia. São Paulo: Mestre Jou.

Andrade, A. N. (1996). A angústia frente ao Caos: um estudo genealógico da formação do psicólogo clínico. Tese de Doutorado não-publicada, Pontifícia Universidade de São Paulo, São Paulo.

Conselho Federal de Psicologia. (1988). Quem é o psicólogo brasileiro. São Paulo: Edicom

Conselho Federal de Psicologia. (1994). Psicólogo brasileiro. Práticas emergentes e desafios para a formação. São Paulo: Casa do Psicólogo.

Conselho Regional de Psicologia. (1994). Uma profissão chamada psicologia. São Paulo: Autor.

Enriquez, E. (1997). A organização em análise. Petrópolis: Vozes.

Figueiredo, L. C. (1994). A invenção do psicológico. São Paulo: Escuta/EDUC.

Figueiredo, L. C. (1995). Revisitando as psicologias: da Epistemologia à Ética nas práticas e discursos da psicologia. Petrópolis/São Paulo: Vozes/EDUC.

Freitas, M. F. Q. (1994). Prácticas en comunidad y psicología comunitaria. In M. Montero (Org.), Psicologia Social Comunitária (pp. 138-157). Guadalajara, México: Universidad de Guadalajara.

Freitas, M. F. Q. (1996). Psicologia na comunidade, psicologia da comunidade e psicologia social comunitária. In M. H. F. Campos (Org.), Psicologia Social Comunitária (pp. 45-62). Petrópolis: Vozes.

George, M. C. (1992). Histoire e éthique des psychologues. Neutralité ou contrepouvoir. Bulletin de psychologie, 43(394), 172-187.

Lévy, A. (2001). Violência, mudança e desconstrução. In A. Levy (Org.), Cenários sociais e abordagem clínica (pp. 75-89). São Paulo: Escuta. 
Lupo, E. M. N. G. (1995). Uma instituição, um rio: histórias de mútuo engendramento. Dissertação de Mestrado não-publicada, Universidade Paulista, São Paulo.

Machado, R. (1990). Deleuze e a filosofia. Rio de Janeiro: Graal.

Machado, R. (1994). Nietzsche e a verdade. Rio de Janeiro: Rocco.

Marton, S. (1993). Nietzsche. A transvaloração dos valores. São Paulo: Moderna.

Montero, M. (1994). Vidas paralelas: psicología comunitaria en Latinoamérica y en Estados Unidos. In M. Montero (Org.), Psicología Social Comunitaria (pp. 23-39). Guadalajara, México: Universidad de Guadalajara.

Morato, H. T. P. (1994). Education in an unstructured milieu (city streets): an experiential viewpoint in action. In International Conference on Client-centered and Experiential Psychotherapies (pp. 74-75) [Abstract]. Viena: Autor.
Morato, H. T. P. (1999). Aconselhamento psicológico: uma passagem para a transdisciplinaridade. In H. T. P. Morato (Org.), Aconselhamento psicológico centrado na pessoa: novos desafios (pp. 61-89). São Paulo: Casa do Psicólogo.

Morin, E. (1990). Ciência com consciência. Lisboa: Publicações Europa-América.

Naffah Neto, A. (1994). A psicoterapia em busca de Dionisio: Nietzsche visita Freud. São Paulo: EDUC/Escuta.

Pellegrino, H. (1983). Pacto edípico e pacto social. Folha de São Paulo, 11/09/83.

Vieira Filho, N. G. (1997). L'Analyste et le quotidien. Le circuit institutionnel, pratiques de formation / analyse. Paris: Ed. Université Paris VIII.

Webster's New Collegiate Dictionary (1974). Springsfield, Massachusetts: C\&C Merriam.

1 Outras discussões sobre essa problemática da ética vs moral, podem ser encontradas em Naffah Neto (1994) e Figueiredo (1995).

2 Trecho escrito a partir da colaboração de André Prado Nunes, Fernando Milton de Almeida, Heloísa Antonelli Aun e Tatiana Benevides Magalhães Braga, pós-graduandos do IPUSP.

3 O significado da palavra ethos, presente nesse momento, é o adotado por Figueiredo, referindo-se ao conjunto de valores, posturas e hábitos considerados como uma moradia, parte do mundo na qual podemos nos sentir relativamente abrigados, levando-se em conta que o significado etimológico de ethos, palavra da qual se origina ética, refere-se tanto aos costumes quanto à morada (Figueiredo, 1995).

4 A contraposição entre sujeito e indivíduo é tomada no sentido referido por Enriquez (1994): indivíduo se refere àquele que assimila seu meio social e os modos de ser e fazer nele presentes sem questionamento; já sujeito se refere àquele que, embora os assimilando, é capaz de refletir e fazer surgir o novo, revelando, assim, aspectos de anormalidade dentro da norma.

5 A palavra chaos, neste texto, é tomada em seu sentido etimológico grego, significando "todas as possibilidades".

6 LEFE - Laboratório de Estudos e Prática em Psicologia Fenomenológica e Existencial do I.P./USP.

7 Urgência é aqui usada no seu sentido etimológico de precisão, necessidade.

8 Subjetivação é aqui compreendida como modos de se constituir o homem no mundo entre outros.

9 Cartografar inclui o acompanhamento, em campo, das vibrações/ pulsações configuradas na práxis cotidiana.

10 Emergência refere-se aquilo que emerge e/ou assoma como crise, a partir da urgência negligenciada.

Ângela Nobre de Andrade é professora no Programa de Pós-Graduação em Psicologia da Universidade Federal do Espírito Santo. Endereço para correspondência: Rua Ludwik Macal, 1145, Apto 301, Jardim da Penha; Vitória, ES; CEP29060-030. Tel.: (27) 3225-1081. Fax: 3335-2501. E-mail: anobre@ terra.com.br Henriette Tognetti Penha Morato é professora no Instituto de Psicologia da Universidade de São Paulo, onde integra o Laboratório de Estudos e Prática Psicológica Fenomenológica e Existencial (LEFE). E-mail: hmorato@usp.br 